\title{
Manajemen Pemupukan Kelapa Sawit (Elaeis Guineensis Jacq.), Studi Kasus pada Kebun Sungai Sagu, Riau
}

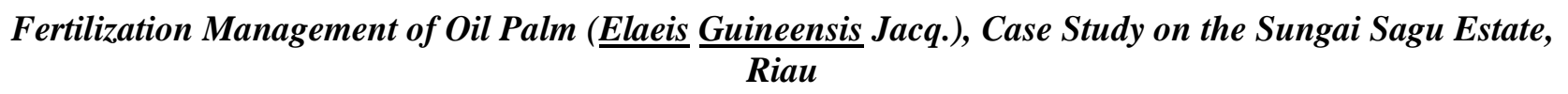

Rahmi Khalida dan Adolf Pieter Lontoh*

Departemen Agronomi dan Hortikultura, Fakultas Pertanian, Institut Pertanian Bogor (Bogor Agricultural University), Jl. Meranti, Kampus IPB Darmaga, Bogor 16680, Indonesia

Telp.\& Faks. 62-251-8629353 e-mail agrohort@ apps.ipb.ac.id

*Penulis Korespondensi: alfpieterl@yahoo.com

Disetujui : 26 November 2018 / Published Online 06 Mei 2019

\begin{abstract}
The research was conducted on February 5th until June 4th 2018 at Sei Sagu Estate, Riau. Oil palm fertilization should be managed well for effectiveness and efficiency according to $6 R$ principles (right type, right dose, right time, right method, right place, right instrument, and right price). Therefore, some observations were included in this research, i.e. $6 R$ fertilization principles, losses of fertilizer, and worker performance. The results show that fertilization activities in Sei Sagu Estate have been properly managed according to Standard Operational Procedure (SOP) of the company. The right dose of mechanical fertilization was observed from the result of paper trap test and the right type of fertilizer was proved through nutrient test using fertilizer kit. The accuracy of 6R principles application was more than $90 \%$. The sower has work performance with an average work performance exceeding the standards of $4.58 \mathrm{ha} \mathrm{WD}^{-1}$ or $491.07 \mathrm{~kg}$ $W D^{-1}$. The amount of fertilizer loss in manual and mechanical fertilization is very small and is considered not detrimental to the company, which is equal to $0.14 \%$ on manual fertilization and $0.09 \%$ on mechanical fertilization.
\end{abstract}

Keywords: 6R fertilization, fertilizer kit, losses of fertilizer, paper trap

ABSTRAK

Kegiatan penelitian dilaksanakan di Kebun Sei Sagu, Riau pada tanggal 5 Februari 2018 hingga 4 Juni 2018. Pemupukan perlu dikelola dengan baik untuk mencapai efektivitas dan efisiensi. Pengamatan dilakukan terhadap manajemen pemupukan meliputi kaidah 6T (tepat jenis, tepat dosis, tepat waktu, tepat cara, tepat tempat, dan tepat alat), kehilangan pupuk (losses), dan prestasi kerja penabur. Hasil pengamatan menunjukkan manajemen pemupukan di Kebun Sei Sagu telah dilaksanakan dengan baik sesuai dengan standar perusahaan. Ketepatan dosis pada pemupukan mekanis diamati dari hasil uji paper trap dan ketepatan jenis dibuktikan melalui uji hara menggunakan perangkat uji pupuk. Rata-rata persentase ketepatan menurut kaidah $6 \mathrm{~T}$ ialah lebih dari 90\%. Tenaga penabur yang digunakan memiliki prestasi kerja dengan rata-rata prestasi kerja melebihi standar yaitu $4.58 \mathrm{ha} \mathrm{HK}^{-1}$ atau $491.07 \mathrm{~kg} \mathrm{HK}^{-1}$. Jumlah kehilangan pupuk pada pemupukan manual dan mekanis sangat kecil dan dianggap tidak merugikan perusahaan, yaitu sebesar $0.14 \%$ pada pemupukan manual dan $0.09 \%$ pada pemupukan mekanis.

Katakunci: 6T pemupukan, kehilangan pupuk, paper trap, perangkat uji pupuk 


\section{PENDAHULUAN}

Kelapa sawit merupakan komoditas perkebunan terbesar dan sangat potensial di Indonesia. Komoditas ini menduduki peringkat kedua setelah padi dalam hal perputaran ekonomi. Hal tersebut terkait dengan peranan kelapa sawit sebagai sumber penghasil minyak nabati yang memiliki potensi hasil tertinggi minyak per satuan luas dibandingkan dengan tanaman lainnya. Minyak kelapa sawit dimanfaatkan sebagai minyak masak, minyak industri, dan bahan bakar. Minyak kelapa sawit juga digunakan sebagai bahan baku berbagai industri mulai dari makanan, logam, hingga kosmetika (Lubis dan Widanarko, 2011).

Tanaman kelapa sawit merupakan tanaman yang berumur panjang. Pertumbuhan dan perkembangannya bergantung pada ketersediaan unsur hara. Lahan sebagai salah satu penyedia unsur hara memiliki kemampuan yang terbatas dalam memenuhi kebutuhan tanaman. Keterbatasan tersebut dapat diimbangi melalui pemupukan. Pemupukan merupakan kegiatan penambahan satu atau beberapa unsur hara untuk memelihara tersedianya unsur hara tersebut dan meningkatkan kesuburan tanah (Pahan, 2011). Pemupukan dapat menggantikan unsur hara yang diabsorpsi tanaman ataupun hilang kerena pencucian serta menjaga kondisi tanah yang ideal bagi pertumbuhan dan perkembangan kelapa sawit (Arsyad et al., 2012).

Kelapa sawit memerlukan beberapa jenis pupuk yang mengandung unsur hara makro $(\mathrm{N}, \mathrm{P}$, dan $\mathrm{K}$ ), sekunder (Ca dan $\mathrm{Mg}$ ), dan mikro (B, $\mathrm{Zn}$, dan $\mathrm{Cu}$ ) (Setyamidjaja, 2006). Jenis pupuk yang diberikan dapat berupa pupuk organik ataupun kimia. Pupuk organik dapat berasal dari limbah padat ataupun cair kelapa sawit. Limbah padat berupa tandan kosong kelapa sawit dimanfaatkan sebagai pupuk organik dalam bentuk kompos (Haryanti et.al., 2014). Limbah cair kelapa sawit diperoleh dari hasil pengolahan pabrik kelapa sawit. Selain bermanfaat bagi tanah dan tanaman, aplikasi limbah kelapa sawit sebagai pupuk merupakan salah satu upaya mengurangi pencemaran lingkungan sebagai bentuk pelaksanaan pertanian yang berkelanjutan.

Pemupukan menjadi faktor utama perhitungan biaya produksi karena lebih dari $50 \%$ biaya digunakan untuk kegiatan ini (Hakim, 2007). Pemupukan kelapa sawit yang baik harus mengacu pada faktor efektivitas dan efisiensi yang maksimum (Pahan, 2011). Efektivitas dan efisiensi pemupukan dapat dicapai dengan mengacu lima tepat pemupukan (kaidah 5T), yaitu tepat jenis, tepat dosis, tepat waktu, tepat cara, dan tepat sasaran (Pardamean, 2014). Pahan (2011) menyatakan penentuan jenis pupuk didasarkan pada sifat pupuk, sifat tanah, harga pupuk, dan kebutuhan pupuk per satuan luas. Waktu pelaksanaan pemupukan berdasarkan iklim (curah hujan), sifat fisik tanah, logistik pupuk, serta sifat sinergis dan antagonis unsur hara. Aplikasi yang tepat cara dan sasaran mengupayakan pupuk dapat mencapai zona perakaran dengan cepat dan tidak mudah menguap karena penguapan dan aliran permukaan.

Kelima faktor di atas harus menjadi perhatian bagi pembuat rekomendasi pupuk dan pengusaha perkebunan. Pembuat rekomendasi pupuk yang berasal dari balai penelitian atau departemen penelitian dan pengembangan perusahaan menentukan dosis, jenis, frekuensi, dan cara aplikasi berdasarkan hasil analisis tanah dan jaringan tanaman (daun), potensi pertumbuhan dan produksi, perawatan tanaman sebelumnya, dan penilaian lingkungan tumbuh. Pengusaha perkebunan berperan dalam aspek perencanaan, pelaksanaan, dan pengawasan pemupukan (Pahan, 2011). Menurut Pardamean (2014) pengawasan yang ketat dari asisten lapang juga harus dilakukan agar kaidah 5T dapat dilaksanakan dengan baik sehingga efektivitas dan efisiensi pemupukan tercapai.

Tujuan penelitian ini adalah mengalisis efisiensi dan efektifitas pemupukan pada kebun kelapa sawit

\section{METODE}

Kegiatan penelitian dilaksanakan pada tanggal 5 Februari 2018 hingga 4 Juni 2018. Kegiatan ini berlokasi di Kebun Sei Sagu Indragiri Hulu, Riau. Data yang diamati meliputi

1) Ketepatan jenis pupuk. Data ketepatan jenis pupuk diperoleh dengan membandingkan jenis pupuk yang direalisasikan di lapangan dengan rencana perusahaan. Ketepatan jenis pupuk juga diperoleh dari pengujian uji hara secara langsung terhadap beberapa sampel pupuk menggunakan perangkat Uji Pupuk (PUP).

2) Ketepatan dosis pupuk. Data ketepatan dosis diambil dari pemupukan manual dan mekanis. Pengamatan tepat dosis pemupukan manual dilakukan dengan mengamati banyaknya taburan pupuk per tanaman kemudian dibandingkan dengan standar perusahaan berdasarkan dosis rekomendasi yang ditetapkan. Pengamatan dilakukan pada 5 orang penabur dengan 3 blok sebagai ulangan dan dari tiap penabur diambil 15 tanaman sebagai contoh yang diamati. Data tepat dosis 
pada pemupukan mekanis diperoleh melalui hasil uji Paper Trap menggunakan alat mekanis berupa conycom.

3) Ketepatan waktu pemupukan. Data ketepatan waktu diperoleh dengan mengamati realisasi waktu pemupukan di lapangan kemudian dibandingkan dengan rencana perusahaan dan curah hujan pada saat pemupukan dilaksanakan.

4) Ketepatan cara pemupukan. Data ketepatan cara pemupukan diperoleh dari pengamatan terhadap cara penaburan pupuk secara manual, yaitu cara tebar (broadcast system) dan cara benam (pocket system) yang dilakukan oleh penabur kemudian dibandingkan dengan standar perusahaan. Masing-masing pengamatan menggunakan 3 blok sebagai ulangan. Pengamatan pada sistem tebar dilakukan terhadap 5 orang penabur dengan masing-masing 15 tanaman contoh, sedangkan pengamatan sistem benam dilakukan pada 3 orang penabur dengan 10 tanaman contoh. Adanya perbedaan jumlah pengamatan dikarenakan perbedaan kondisi dan situasi di lapangan.

5) Ketepatan tempat pemupukan. Data ketepatan tempat pemupukan diperoleh dari pengamatan terhadap jarak penaburan pupuk secara manual yang terdekat dari batang tanaman pada TBM dan TM lalu dibandingkan dengan standar perusahaan. Data pengamatan ketepatan tempat sama dengan ketepatan cara.

6) Ketepatan alat pemupukan. Data ketepatan alat pemupukan diperoleh pada pemupukan manual dengan mengamati alat yang digunakan pada saat aplikasi pemupukan oleh penabur di lapangan kemudian dibandingkan dengan standar perusahaan. Pengamatan dilakukan pada 5 orang penabur dengan 3 blok sebagai ulangan.

7) Kehilangan pupuk. Pengamatan kehilangan pupuk yang akan diamati dimulai dari penerimaan pupuk di gudang, pengeceran, hingga penaburan pupuk di lapangan. Pengambilan contoh dilakukan pada pemupukan manual dan mekanis dengan masing-masing 3 kali ulangan (truk sebagai ulangan).

8) Prestasi tenaga kerja. Data prestasi tenaga kerja diperoleh dengan dari jumlah tenaga kerja, jumlah pupuk yang ditabur dan luasan areal yang dipupuk kemudian dibandingkan dengan standar perusahaan.

Analisis data dilakukan secara kualitatif dan kuantitatif. Analisis kualitatif berupa penjabaran mengenai seluruh data dan informasi yang diperoleh di lapangan. Analisis kuantitatif digunakan dalam pengolahan data berupa perhitungan secara matematis meliputi nilai ratarata dan persentase hasil pengamatan, dan uji $t$ student. Seluruh data kemudian diuraikan secara deskriptif dengan membandingkan terhadap standar perusahaan, norma baku pada perkebunan kelapa sawit secara umum, dan literatur.

\section{HASIL DAN PEMBAHASAN}

\section{Kondisi Umum}

Kebun Sei Sagu secara geografis berada pada $0^{\circ} 18^{\prime} 9.0695^{\prime \prime}$ Lintang Selatan dan $102^{\circ} 16^{\prime}$ 23.0914" Bujur Timur. Kebun Sei Sagu terlerak pada dua kecamatan di Kabupaten Indragiri Hulu, yaitu Kecamatan Lirik dan Pasir Penyu. Rata-rata curah hujan per tahun dalam kurun waktu 5 tahun terakhir (2013 - 2017) ialah $1625 \mathrm{~mm}$ dengan puncak curah hujan pada bulan April dan November. Berdasarkan klasifikasi iklim SchmidtFerguson, Kebun Sei Sagu termasuk ke dalam tipe iklim C (agak basah) dengan rata-rata 7 bulan basah dan 4.6 bulan kering per tahun. Jenis tanah yang dominan ialah tanah mineral dengan kelas kesesuaian lahan S2. Kebun Sei Sagu dibagi menjadi 4 afdeling dengan luas areal menghasilkan dan belum menghasilkan masingmasing sebesar 3154.10 ha dan 348.22 ha. Produksi rata-rata Kebun Sei Sagu dalam 5 tahun terakhir ialah 72043.2 ton tahun $^{-1}$ dengan produktivitas sebesar 21.36 ton ha' ${ }^{-1}$.

Pemupukan di Kebun Sei Sagu diaplikasikan secara manual dan mekanis. Pemupukan dikelola dengan manajemen yang baik untuk mencapai efisiensi dan efektivitas pemupukan sesuai dengan kaidah tepat pemupukan. Manajemen pemupukan kelapa sawit terdiri atas penentuan dosis rekomendasi dan jenis pupuk yang akan digunakan, kecukupan jumlah tenaga kerja, waktu pelaksanaan, kesiapan lahan, organisasi pemupukan, pelaksanaan pemupukan di lapangan dan pengawasan atau sistem kontrol pemupukan.

\section{Ketepatan Jenis Pupuk}

Jenis pupuk yang umum digunakan untuk tanaman kelapa sawit ialah pupuk tunggal dan majemuk yang dibedakan berdasarkan jumlah hara (Pahan, 2011). Pupuk tunggal dapat menyediakan hara yang dibutuhkan secara langsung dan tepat. Akan tetapi, pupuk majemuk lebih efisien daripada pupuk tunggal ditinjau dari segi distribusi, penyimpanan, dan aplikasi. Penggunaan pupuk tunggal di Kebun Sei Sagu lebih dominan di areal TBM, sedangkan pupuk majemuk di areal TM. 
Ketepatan jenis pupuk dibuktikan melalui pengujian kandungan unsur hara menggunakan Perangkat Uji Pupuk (PUP). Akan tetapi, persentase kandungan hara pada pengujian tersebut tidak dapat ditentukan dengan angka yang tepat, melainkan kisaran persentase yang diperoleh berdasarkan perbandingan perubahan warna reaksi pupuk dengan colour chart yang terdapat pada perangkat. Hasil yang diperoleh ialah kandungan hara pada pupuk berada pada kisaran persentase yang mendekati dengan kandungan hara yang sesungguhnya, sehingga dapat dinyatakan bahwa pupuk yang digunakan merupakan pupuk asli dan tepat jenis sesuai dengan rekomendasi perusahaan (Tabel 1).

Tabel 1. Hasil uji hara berbagai jenis pupuk di Kebun Sei Sagu

\begin{tabular}{|c|c|c|c|}
\hline $\begin{array}{l}\text { Jenis } \\
\text { Pupuk }\end{array}$ & $\begin{array}{l}\text { Unsur Hara } \\
\text { yang Diuji }\end{array}$ & Reaksi & $\begin{array}{c}\text { Kandungan } \\
\text { Hara }\end{array}$ \\
\hline Urea & $\mathrm{N}$ & $\begin{array}{l}\text { Kuning-hijau } \\
\text { tua }\end{array}$ & $>20 \%$ \\
\hline \multirow{3}{*}{$\begin{array}{l}\text { NPK } \\
15-6-24\end{array}$} & $\mathrm{~N}$ & Kuning-hijau & $10-15 \%$ \\
\hline & $\mathrm{P}_{2} \mathrm{O}_{5}$ & Kuning & $5-10 \%$ \\
\hline & $\mathrm{K}_{2} \mathrm{O}$ & $\begin{array}{l}\text { Ada endapan } \\
\text { putih }\end{array}$ & $20-30 \%$ \\
\hline NPK & $\mathrm{N}$ & Kuning-hijau & $10-15 \%$ \\
\hline $12-12-17$ & $\mathrm{P}_{2} \mathrm{O}_{5}$ & Kuning muda & $5 \%$ \\
\hline$+2.5 \mathrm{~B}$ & $\mathrm{~K}_{2} \mathrm{O}$ & putih & $20-30 \%$ \\
\hline MOP & $\mathrm{K}_{2} \mathrm{O}$ & $\begin{array}{l}\text { Ada endapan } \\
\text { putih }\end{array}$ & $60 \%$ \\
\hline
\end{tabular}

Ketepatan jenis pupuk juga diamati dengan cara membandingkan jenis pupuk yang direalisasikan di lapang dengan jenis pupuk rekomendasi perusahaan. Hasil pengamatan menunjukkan seluruh pupuk yang diaplikasikan sudah sesuai dengan rekomendasi yang direncanakan perusahaan (Tabel 2).

\section{Ketepatan Dosis Pemupukan}

Penentuan dosis pupuk didasarkan atas beberapa pertimbangan, yaitu hasil analisis daun dan tanah, realisasi produksi 5 tahun sebelumnya, realisasi pemupukan tahun sebelumnya, data curah hujan minimal 5 tahun sebelumnya, serta hasil pengamatan lapang yang meliputi gejela defisiensi hara, kultur teknis, panen, dan kesuburan tanah (Pahan, 2011). Penentuan dosis perjenis pupuk di
Tabel 2. Realisasi jenis pupuk pada areal TM Semester I di Kebun Sei Sagu

\begin{tabular}{|c|c|c|}
\hline \multirow{2}{*}{ Jenis pupuk } & \multicolumn{2}{|c|}{ Realisasi } \\
\hline & Unsur hara & Kandungan \\
\hline \multirow{4}{*}{ NPK 17-7-21 } & $\mathrm{N}$ & $17 \%$ \\
\hline & $\mathrm{P}_{2} \mathrm{O}_{5}$ & $7 \%$ \\
\hline & $\mathrm{K}_{2} \mathrm{O}$ & $21 \%$ \\
\hline & Kadar air & $3 \%$ \\
\hline \multirow{4}{*}{ NPK 15-9-21 } & $\mathrm{N}$ & $15 \%$ \\
\hline & $\mathrm{P}_{2} \mathrm{O}_{5}$ & $9 \%$ \\
\hline & $\mathrm{K}_{2} \mathrm{O}$ & $21 \%$ \\
\hline & Kadar air & $3 \%$ \\
\hline \multirow{4}{*}{ NPK 15-6-24 } & $\mathrm{N}$ & $15 \%$ \\
\hline & $\mathrm{P}_{2} \mathrm{O}_{5}$ & $6 \%$ \\
\hline & $\mathrm{K}_{2} \mathrm{O}$ & $24 \%$ \\
\hline & Kadar air & $3 \%$ \\
\hline Kaptan & $\mathrm{CaO}$ & $50 \%$ \\
\hline $\mathrm{Cu}$ Etda & $\mathrm{Cu}$ & $\begin{array}{c}14.5 \%- \\
15.5 \%\end{array}$ \\
\hline \multirow{4}{*}{ Borate } & $\mathrm{B}_{2} \mathrm{O}_{3}$ & $46 \%$ \\
\hline & $\mathrm{Na}_{2} \mathrm{O}$ & $20 \%$ \\
\hline & $\mathrm{SO}_{4}$ & $0.02 \%$ \\
\hline & $\mathrm{Cd}$ & $<0.01 \mathrm{ppm}$ \\
\hline \multirow{2}{*}{ Kiserit } & $\mathrm{MgO}$ & $26 \%$ \\
\hline & $\mathrm{S}$ & $21 \%$ \\
\hline
\end{tabular}

Kebun Sei Sagu atau PT TPP secara umum dilakukan oleh Tim Agronomy Services di Jakarta. Dosis pupuk TBM ditetapkan atas dasar standar baku atau referensi yang sudah ada dari Pusat Penelitian Kelapa Sawit (PPKS), sedangkan dosis pupuk TM ditetapkan berdasarkan hasil analisa daun dan tanah yang dilaksanakan setiap semester.

Kunci ketepatan dosis terletak pada kalibrasi alat yang digunakan. Pemupukan manual pada pengamatan menggunakan mangkok sebagai takaran yang bentuknya seragam untuk setiap penabur. Kalibrasi takaran dilakukan dengan menimbang mangkok yang berisi pupuk. Satu mangkok dapat diisi penuh $0.75 \mathrm{~kg}$ pupuk. Dosis rekomendasi yang diaplikasikan ialah $2.25 \mathrm{~kg}$, sehingga diperlukan 3 mangkok untuk satu tanaman. Rata-rata jumlah tanaman tepat dosis dari total 75 tanaman yang diamati ialah 69 tanaman dengan persentase 92\% (Tabel 3). Hasil tersebut sudah baik dan diterima oleh perusahaan. Faktor utama penyebab ketidaktepatan dosis ialah

Tabel 3. Ketepatan dosis pemupukan NPK 15-6-24 di Afdeling OC Kebun Sei Sagu

\begin{tabular}{lcccccr}
\hline Blok & $\begin{array}{c}\text { Jumlah Tanaman } \\
\text { yang Diamati }\end{array}$ & $\begin{array}{c}\text { Dosis Tanaman } \\
(\mathrm{kg})\end{array}$ & $\begin{array}{c}\text { Dosis Sesuai } \\
(\text { tanaman) }\end{array}$ & $\begin{array}{c}\text { Dosis Tidak } \\
\text { Sesuai (tanaman) }\end{array}$ & $\begin{array}{c}\text { Tepat } \\
\text { Dosis }(\%)\end{array}$ & $\begin{array}{c}\text { Tidak Tepat } \\
\text { Dosis }(\%)\end{array}$ \\
\hline OC09 & 75 & 2.25 & 69 & 6 & 92.00 & 8.00 \\
OC22 & 75 & 2.25 & 70 & 5 & 93.33 & 6.67 \\
OC25 & 75 & 2.25 & 67 & 8 & 89.33 & 10.67 \\
Rata-rata & & & 69 & 6 & 92.00 & 8.00 \\
\hline
\end{tabular}


Tabel 4. Hasil uji ketepatan dosis (Uji Paper Trap) pemupukan mekanis di afdeling OA Kebun Sei Sagu

\begin{tabular}{cccccccc}
\hline Blok & Jenis & Dosis $(\mathrm{kg}$ & Berat Pupuk & Batas & Batas & \multicolumn{2}{c}{ Hasil Paper Trap (\%) } \\
\cline { 6 - 8 } & Pupuk & $\left.\operatorname{tanaman}^{-1}\right)$ & Standar $(\mathrm{kg})$ & Bawah $(\mathrm{kg})$ & Atas $(\mathrm{kg})$ & Berat Pupuk $(\mathrm{kg})$ & Keterangan \\
\hline OA11 & NPK & 2.25 & 0.54 & 0.48 & 0.58 & 0.53 & Tepat dosis \\
\hline
\end{tabular}

kurangnya ketelitian penabur karena mengejar target agar pekerjaan cepat selesai, serta kurangnya pengawasan dari mandor pada saat penaburan berlangsung.

Ketepatan dosis pemupukan mekanis ditentukan dari hasil Uji Paper Trap. Uji Paper Trap dilakukan pada unit mekanisasi baik dari jenis traktor atau Conycom di setiap awal periode pemupukan. Pengujian ini bertujuan membuktikan variasi dosis pada berbagai kecepatan dan RPM yang dihasilkan dari kalibrasi jalan dan kalibrasi diam alat mekanisasi. Prinsip pengujian ini ialah membandingkan bobot pupuk yang dikeluarkan unit mekanisasi pada 3 terpal penampung sewaktu aplikasi dengan standar yang telah ditentukan. Alat dinyatakan tepat dosis apabila dosis blok hasil Paper Trap berada di antara batas bawah dengan batas atas, dan sebaliknya. Alat yang tidak tepat dosis harus distandarisasi dan dikalibrasi kembali. Pengamatan dilakukan pada dosis 2.25 $\mathrm{kg}$ tanaman-1 dengan menggunakan kecepatan kelinci dan RPM 2500. Bobot pupuk hasil paper trap ialah $0.53 \mathrm{~kg}$ sedangkan standar bobot dengan deviasi $\pm 10 \%$ masing-masing ialah $0.48 \mathrm{~kg}$ dan $0.58 \mathrm{~kg}$. Hasil pengamatan pada menunjukkan berat pupuk di 3 terpal berada di antara batas bawah dan batas atas dari standar berat yang ditetapkan, sehingga alat sudah tepat dosis dan dapat digunakan untuk melaksanakan pemupukan mekanis (Tabel 4).

\section{Ketepatan Waktu Pemupukan}

Pemupukan di Kebun Sei Sagu ditentukan oleh Tim Agronomy Services di Jakarta yang dibagi menjadi 2 semester dalam 1 tahun berdasarkan pola curah hujan per wilayah selama 5 tahun terakhir. Kebun Sei Sagu memiliki tipe curah hujan ekuatorial, sehingga waktu yang diperbolehkan untuk aplikasi pemupukan ialah bulan Januari - Maret (semester 1) dan bulan Juli - September (semester 2). Berdasarkan pengamatan, realisasi waktu pemupukan di Kebun Sei Sagu sudah sesuai dengan waktu rekomendasi yang ditentukan (Tabel 5). Ketepatan waktu aplikasi didukung pula dengan ketepatan pengadaan pupuk dan kesiapan lapangan sehingga pemupukan dapat dilaksanakan sesuai dengan perencanaan.

Nunyai et al. (2016) menyatakan manajemen waktu pemupukan diperlukan untuk memastikan terserapnya pupuk secara efektif
Tabel 5. Rencana dan realisasi waktu pemupukan TM semester I tahun 2018 di Kebun Sei Sagu

\begin{tabular}{|c|c|c|}
\hline \multirow[t]{2}{*}{ Jenis Pupuk } & $\begin{array}{c}\text { Rencana } \\
\text { Pemupukan }\end{array}$ & $\begin{array}{c}\text { Realisasi } \\
\text { Pemupukan }\end{array}$ \\
\hline & \multicolumn{2}{|c|}{ Bulan Aplikasi } \\
\hline NPK.17-7-21 & Januari-Maret & Januari-Februari \\
\hline NPK 15-9-21 & Januari-Maret & Februari \\
\hline NPK 15-6-24 & Januari-Maret & Januari-Februari \\
\hline Kaptan & Januari-Maret & Januari-Februari \\
\hline $\mathrm{Cu}$ Edta & Januari-Maret & Maret \\
\hline Borate & Januari-Maret & Februari \\
\hline Kieserit & Januari-Maret & Februari \\
\hline
\end{tabular}

oleh tanaman. Waktu dan frekuensi pemupukan dipengaruhi oleh iklim terutama curah hujan, sifat fisik tanah, pengadaan pupuk, serta adanya sifat sinergis dan antagonis antar unsur hara. Pemupukan dapat diserap secara maksimal oleh tanaman apabila curah hujan $100-250$ $\mathrm{mm} /$ bulan (Pahan, 2011). PPKS (2007) menyatakan curah hujan minimum untuk pemupukan yaitu $60 \mathrm{~mm}$ bulan $^{-1}$ dan curah hujan maksimum $300 \mathrm{~mm}$ bulan $^{-1}$. Hal tersebut bertujuan menghindari kehilangan pupuk akibat pencucian maupun penguapan. Rata-rata curah hujan dari bulan Januari - Maret 2018 ialah 195.8 $\mathrm{mm}$ bulan $^{-1}$ (Tabel 6), sehingga telah memenuhi standar curah hujan untuk dilakukan pemupukan.

Tabel 6. Curah hujan di PT TPP periode Januari - Maret 2018

\begin{tabular}{lcc}
\hline Bulan & Hari Hujan & Curah Hujan $(\mathrm{mm})$ \\
\hline Januari & 4 & 157.50 \\
Februari & 6 & 148.00 \\
Maret & 9 & 282.00 \\
Rata-rata & 6 & 195.80 \\
\hline
\end{tabular}

Sumber: Kantor Besar PT Tunggal Perkasa Plantation (2018)

\section{Ketepatan Cara Pemupukan}

Penentuan cara aplikasi pupuk dilakukan dengan beberapa pertimbangan, diantaranya jenis pupuk, topografi lahan, dan kondisi drainase tanah. Terdapat dua cara yang umumnya diterapkan di perkebunan kelapa sawit, yaitu sistem tebar (broadcast system) dan sistem benam (pocket system). Sistem tebar dilakukan dengan menebar pupuk secara langsung di daerah piringan, sedangkan sistem benam dilakukan dengan menabur pupuk pada lubang yang telah dibuat di sekitar piringan (Pahan, 2011). 
Tabel 7. Ketepatan cara pemupukan NPK dan Cu Edta di Kebun Sei Sagu

\begin{tabular}{lcccccc}
\hline Blok & $\begin{array}{c}\text { Jenis } \\
\text { Pupuk }\end{array}$ & Cara & $\begin{array}{c}\text { Jumlah Tanaman } \\
\text { yang Diamati }\end{array}$ & $\begin{array}{c}\text { Tepat Cara } \\
\text { (tanaman) }\end{array}$ & $\begin{array}{c}\text { Tidak Tepat Cara } \\
\text { (tanaman) }\end{array}$ & $\begin{array}{c}\text { Tepat Cara } \\
(\%)\end{array}$ \\
\hline OA01 & NPK & Tebar & 75 & 72 & 3 & 96.00 \\
OA02 & NPK & Tebar & 75 & 71 & 4 & 94.67 \\
OA03 & NPK & Tebar & 75 & 70 & 5 & 93.33 \\
\hline Rata-rata & & & 71 & 4 & 94.67 \\
\hline OA10 & CuEdta & Benam & 30 & 0 & 0 & 100.00 \\
OA14 & CuEdta & Benam & 30 & 0 & 0 & 100.00 \\
OA15 & CuEdta & Benam & 30 & 0 & 0 & 100.00 \\
\hline \multicolumn{2}{l}{ Rata-rata } & & & 0 & 0 & 100.00 \\
\hline
\end{tabular}

Pemupukan di Kebun Sei Sagu diaplikasikan dengan sistem tebar hampir untuk seluruh jenis pupuk, kecuali $\mathrm{Cu}$ Edta. Penerapan sistem tebar dimungkinkan untuk seluruh areal Kebun Sei Sagu karena topografi yang cukup landai. Berdasarkan jenisnya, pupuk $\mathrm{Cu}$ Edta sebenarnya dapat ditebar secara langsung di piringan. Akan tetapi, pupuk $\mathrm{Cu}$ Edta mengandung zat yang berbahaya bagi hewan ternak di sekitar kebun, sehingga aplikasi pupuk harus dibenamkan di dalam tanah untuk menghindari resiko kematian ternak. Berdasarkan pengamatan, ketepatan cara pemupukan NPK dan $\mathrm{Cu}$ Edta sudah sangat baik dengan persentase masing-masing mencapai $94.67 \%$ dan $100 \%$ (Tabel 7). Ketidaktepatan cara pada sistem tebar dikarenakan kesalahan penabur yang melakukan penaburan pada satu sisi piringan terutama pada tanaman-tanaman tanaman yang terakhir dipupuk dalam satu gawangan. Aplikasi pupuk $\mathrm{Cu}$ Edta dengan sistem benam dilakukan dengan tepat karena pengawasan yang dilakukan lebih intensif mengingat keselamatan hewan ternak di sekitar sehingga tidak menimbulkan kerugian yang besar.

\section{Ketepatan Tempat Pemupukan}

Penempatan pupuk pada kelapa sawit dilakukan dengan mempertimbangkan penyebaran akar tanaman yang aktif menyerap unsur hara dalam tanah (Pardamean, 2017). Pemberian pupuk secara rutin dan merata di piringan berdiameter 1,5 $\mathrm{m}$ akan merangsang perkembangan akar ke arah permukaan untuk mendapatkan hara. Tempat aplikasi pupuk di Kebun Sei Sagu ditentukan berdasarkan umur tanaman. Pupuk ditebar merata di dalam piringan dengan jarak $20 \mathrm{~cm}$ pada TBM dan $1 \mathrm{~m}$ pada TM dari pangkal batang tanaman ke bagian luar hingga lingkaran proyeksi tajuk daun. Berdasarkan pengamatan, tempat pemupukan pada aplikasi pupuk NPK (TBM) ialah $59.7 \mathrm{~cm}$ dan pupuk CuEdta (TM) ialah $116.9 \mathrm{~cm}$. Hasil uji statistik menggunakan t-student pada taraf 5\% menunjukkan bahwa kedua nilai tidak berbeda nyata dengan standar yang ditetapkan perusahaan (Tabel 8). Oleh karena itu, penempatan pupuk di Kebun Sei Sagu baik pada TBM maupun TM dinyatakan tepat.

\section{Ketepatan Alat Pemupukan}

Ketepatan alat ditambahkan pada pengamatan kaidah tepat pemupukan sebab alat merupakan salah satu faktor pendukung agar efektivitas dan efisiensi pemupukan tercapai. Penggunaan alat disesuaikan dengan metode pemupukan, yaitu manual atau mekanis. Berdasarkan Standard Operational Procedure (SOP) perusahaan, alat-alat yang digunakan pada pemupukan manual terdiri atas takaran berupa mangkok yang telah dikalibrasi, ember plastik dan ayakan tabur. Pemupukan mekanis menggunakan unit mekanisasi dengan jenis traktor atau conycom. Selain itu, alat lain yang wajib digunakan pada kedua metode pemupukan tersebut ialah Alat Pelindung Diri (APD) yang terdiri atas helm, sarung tangan dan sepatu bot.

Tabel 8. Ketepatan tempat pemupukan di areal TBM dan TM Kebun Sei Sagu

\begin{tabular}{lcccc}
\hline Blok & Jenis Pupuk & Jumlah Tanaman yang Diamati & Standar $(\mathrm{cm})$ & Rata-rata $(\mathrm{cm})$ \\
\hline OA01 & NPK & 75 & 20 & $70.5^{\text {tn }}$ \\
OA02 & NPK & 75 & 20 & $55.3^{\text {tn }}$ \\
OA03 & NPK & 75 & 20 & $53.5^{\text {tn }}$ \\
\hline Rata-rata & & 30 & 71 & $59.7^{\text {tn }}$ \\
\hline OA10 & CuEdta & 30 & 100 & $107.8^{\text {tn }}$ \\
OA14 & CuEdta & 30 & 100 & $113.1^{\text {tn }}$ \\
OA15 & CuEdta & & & $130.0^{\text {tn }}$ \\
\hline Rata-rata & & & & $116.9^{\text {tn }}$ \\
\hline
\end{tabular}

Keterangan : tn: tidak berbeda nyata pada uji-t taraf 5\%. 
Tabel 9. Pengamatan ketepatan alat pemupukan di Afdeling OA Kebun Sei Sagu

\begin{tabular}{lcccc}
\hline Blok & $\begin{array}{c}\text { Jumlah Panabur yang } \\
\text { Diamati }\end{array}$ & $\begin{array}{c}\text { Jumlah Penabur Tidak Tepat } \\
\text { Alat }\end{array}$ & $\begin{array}{c}\text { Tidak Tepat Alat } \\
(\%)\end{array}$ & $\begin{array}{c}\text { Tepat Alat } \\
(\%)\end{array}$ \\
\hline OA01 & 5 & - & 0.00 & 100.00 \\
OA02 & 5 & - & 0.00 & 100.00 \\
OA03 & 5 & - & 0.00 & 100.00 \\
\hline Rata-rata & 5 & - & 0.00 & 100.00 \\
\hline
\end{tabular}

Pengamatan dilakukan terhadap kelengkapan alat yang digunakan penabur pada pemupukan NPK yang diaplikasikan secara manual. Pengamatan dilakukan terhadap 5 orang penabur dengan 3 blok sebagai ulangan.

Berdasarkan hasil pengamatan, persentase ketepatan alat untuk seluruh penabur mencapai $100 \%$ (Tabel 9). Hal tersebut menunjukkan bahwa alat yang digunakan sudah tepat dan seluruh penabur telah mengikuti dan mematuhi SOP yang telah ditetapkan perusahaan. Pencapaian tersebut harus dipertahankan dengan tetap memberi pengarahan dan pengawasan agar pekerjaan berlangsung secara optimal dan sesuai dengan perencanaan.

\section{Ketepatan Alat Pemupukan}

Kehilangan pupuk di lahan merupakan salah satu masalah yang harus dihindari dalam pelaksanaan pemupukan. Kehilangan pupuk akan menimbulkan kerugian bagi perusahaan terutama secara finansial. Kehilangan pupuk dapat terjadi karena faktor alam akibat dari penguapan atau aliran permukaan (Sunarko, 2014). Kehilangan pupuk oleh manusia terjadi karena kerusakan karung pupuk pada saat pengeceran atau pupuk sengaja dibuang ke dalam parit/rorak agar pekerjaan selesai lebih awal (Pahan, 2011). Berdasarkan pengamatan, rata-rata kehilangan pupuk NPK pada pemupukan manual ialah $0.14 \%$, sedangkan pada pemupukan mekanis ialah $0.09 \%$ (Tabel 10). Kehilangan pupuk pada kedua metode tersebut terbilang sangat kecil, yaitu kurang dari $0.15 \%$ dan dianggap tidak merugikan perusahaan secara nyata.

Kehilangan pupuk pada pemupukan manual lebih banyak terjadi pada saat pengeceran pupuk dari karung ke ember. Hal tersebut dikarenakan pekerja kurang berhati-hati sehingga pupuk tercecer di tanah dan tidak dipungut kembali. Kehilangan pupuk pada pemupukan mekanis lebih banyak terjadi ketika pengeceran pupuk dari dalam truk ke lahan. Pupuk banyak tercecer di dalam truk karena karung pupuk bocor akibat dari penggunaan gancu. Resiko kehilangan pupuk pada pemupukan manual dapat diminimalisir dengan memberikan terpal atau karung sebagai alas pada saat pengeceran pupuk di tempat pengumpulan pupuk (TPP), sedangkan pada pemupukan mekanis ialah mengumpulkan pupuk yang tertinggal di dalam truk sesaat setelah pupuk diecerkan sehingga pupuk dapat diaplikasikan kembali. Selain itu, diperlukan pengawasan yang lebih intensif terhadap kinerja tenaga pemupukan serta memberikan pengarahan tentang kerugian yang ditimbulkan akibat kehilangan pupuk bagi perusahaan.

\section{Prestasi Tenaga Kerja}

Prestasi tenaga kerja pemupukan bergantung pada dosis rekomendasi, topografi areal, dan keterampilan penabur (Pardamean, 2017). Prestasi kerja pada umumnya berbanding lurus dengan dosis. Semakin tinggi dosis ( $\mathrm{kg}$ tanaman-1), semakin tinggi pula prestasi kerja yang diperoleh oleh tenaga pemupukan ( $\mathrm{kg} \mathrm{HK}$ 1). Prestasi kerja dipengaruhi oleh jumlah tenaga kerja yang digunakan. Jumlah tenaga kerja harus direncanakan sebaik mungkin agar prestasi kerja karyawan dapat tercapai sesuai standar yang ditetapkan.

Pengamatan prestasi kerja penabur dilakukan pada pemupukan NPK secara manual dengan dosis $1.1 \mathrm{~kg} \operatorname{tanaman}^{-1}$. Standar prestasi

Tabel 10. Kehilangan pupuk pada pemupukan NPK di Kebun Sei Sagu

\begin{tabular}{|c|c|c|c|c|c|}
\hline Blok & $\begin{array}{l}\text { Jenis } \\
\text { Pupuk }\end{array}$ & Metode & $\begin{array}{c}\text { Total Pupuk yang } \\
\text { Diaplikasikan }(\mathrm{kg})\end{array}$ & $\begin{array}{c}\text { Total Kehilangan Pupuk } \\
\text { (tanaman) }\end{array}$ & $\begin{array}{c}\text { Kehilangan Pupuk } \\
\text { (kg) }\end{array}$ \\
\hline OA01 & NPK & Manual & 3400 & 5.6 & 0.16 \\
\hline OA02 & NPK & Manual & 5750 & 7.2 & 0.13 \\
\hline OA03 & NPK & Manual & 3050 & 4.7 & 0.15 \\
\hline Rata-rata & & & 4067 & 5.8 & 0.14 \\
\hline OA10 & NPK & Mekanis & 12000 & 10.6 & 0.09 \\
\hline OA14 & NPK & Mekanis & 12000 & 14.4 & 0.12 \\
\hline OA15 & NPK & Mekanis & 10000 & 5.9 & 0.06 \\
\hline Rata-rate & & & & 10.3 & 0.09 \\
\hline
\end{tabular}


Tabel 11. Prestasi kerja penabur di Kebun Sei Sagu

\begin{tabular}{|c|c|c|c|c|c|c|c|c|c|}
\hline \multirow[b]{2}{*}{ Blok } & \multirow[b]{2}{*}{ Dosis (kg) } & \multirow[b]{2}{*}{ Jenis Pupuk } & \multirow[b]{2}{*}{ Luas (ha) } & \multirow[b]{2}{*}{ Total (kg) } & \multirow[b]{2}{*}{ Total HK } & \multicolumn{2}{|c|}{ Standar } & \multicolumn{2}{|c|}{ Prestasi Kerja } \\
\hline & & & & & & ha $\mathrm{HK}^{-1}$ & $\mathrm{~kg} \mathrm{HK}^{-1}$ & ha $\mathrm{HK}^{-1}$ & $\mathrm{~kg} \mathrm{HK}^{-1}$ \\
\hline OA01 & 1.1 & NPK & 31.54 & 3400 & 7 & 3.01 & 450 & 4.51 & 485.71 \\
\hline OA02 & 1.1 & NPK & 53.89 & 5750 & 13 & 3.01 & 450 & 4.49 & 479.17 \\
\hline OA03 & 1.1 & NPK & 28.52 & 3050 & 7 & 3.01 & 450 & 4.75 & 508.33 \\
\hline Rata-rata & & & & & & 3.01 & 450 & 4.58 & 491.07 \\
\hline
\end{tabular}

kerja penabur di Kebun Sei Sagu untuk dosis $1 \mathrm{~kg}$ ialah 400 - $500 \mathrm{~kg} \mathrm{HK}^{-1}$. Standar prestasi kerja yang ditetapkan pada hari pengamatan ialah 450 $\mathrm{kg} \mathrm{HK}^{-1}$ atau 3.01 ha $\mathrm{HK}^{-1}$. Berdasarkan hasil pengamatan, rata-rata prestasi kerja penabur ialah $491.07 \mathrm{~kg} \mathrm{HK}^{-1}$ atau $4.58 \mathrm{ha} \mathrm{HK}^{-1}$ (Tabel 11). Hasil tersebut telah memenuhi standar perusahaan dan menunjukkan bahwa tenaga penabur yang digunakan sudah cukup dan memiliki keterampilan kerja yang baik sehingga mampu menyelesaikan pekerjaan secara efisien dan sesuai dengan rencana kerja yang ditetapkan.

\section{KESIMPULAN}

Manajemen pemupukan di Kebun Sei Sagu telah dilakukan sesuai dengan SOP yang ditetapkan menurut kaidah 6T (tepat jenis, tepat dosis, tepat waktu, tepat cara, tepat tempat dan tepat alat). Penerapan kaidah 6T diperlukan untuk mencapai efektivitas dan efisiensi pemupukan. Realisasi jenis pupuk, waktu pemupukan serta penempatan pupuk telah sesuai dengan rekomendasi perusahaan. Ketepatan dosis pemupukan manual mencapai $92 \%$ dan alat mekanis dinyatakan sudah tepat dosis dan dapat digunakan untuk aplikasi pemupukan. Ketepatan cara pemupukan secara tebar ialah $94.75 \%$, sedangkan sistem benam mencapai $100 \%$. Penggunaan alat telah optimal dengan ketepatan $100 \%$. Kehilangan pupuk sangat kecil yaitu $0.14 \%$ pada pemupukan manual dan $0.09 \%$ pada pemupukan mekanis. Angka tersebut dinyatakan tidak merugikan perusahaan secara nyata. Penabur telah menunjukkan kinerja yang baik dengan ratarata prestasi kerja melebihi standar yaitu 4.58 ha $\mathrm{HK}^{-1}$ atau $491.07 \mathrm{~kg} \mathrm{HK}^{-1}$.

\section{DAFTAR PUSTAKA}

Arsyad, A.R., H. Junedi, F. Yulfita. 2012. Pemupukan kelapa sawit berdasarkan potensi produksi untuk meningkatkan hasil tandan buah segar (TBS) pada lahan marginal Kumpeh. Jurnal Penelitian Universitas Jambi Seri Sains. 14(1): 29-36.

Hakim, M. 2007. Kelapa Sawit Teknis Agronomis dan Manajemennya (Tinjauan Teoritis dan Praktis): Buku Pegangan Agronomis dan Pengusaha Kelapa Sawit. Lembaga Pupuk Indonesia. Jakarta.

Haryanti A., Norsamsi, P.S.F. Sholiha, N.F. Putri. 2014. Studi pemanfaatan limbah padat kelapa sawit. Konversi. 3(2): 20-29.

Lubis, R.E., A. Widanarko. 2011. Buku Pintar Kelapa Sawit. Agromedia, Jakarta.

Nunyai, A.P., S. Zaman, S. Yahya. 2016. Manajemen pemupukan kelapa sawit di Sungai Bahaur Estate, Kalimantan Tengah. Bul. Agrohorti 4(2): 165-172.

Pahan, I. 2011. Panduan Lengkap Kelapa Sawit Manajemen Agribisnis dari Hulu hingga Hilir. Penebar Swadaya. Jakarta.

Pardamean, M. 2014. Mengelola Kebun dan Pabrik Kelapa Sawit secara Profesional. Penebar Swadaya. Jakarta.

Pardamean, M. 2017. Kupas Tuntas Agribisnis Kelapa Sawit. Penebar Swadaya. Jakarta.

[PPKS] Pusat Penelitian Kelapa Sawit. 2007. Budidaya Kelapa Sawit. Pusat Penelitian Kelapa Sawit, Indonesian Oil Palm Research Institute. Medan.

Setyamidjaja, D. 2006. Kelapa Sawit Teknik Budi Daya, Panen, dan Pengolahan. Kanisius. Yogyakarta.

Sunarko. 2014. Budidaya Kelapa Sawit di Berbagai Jenis Lahan. Agromedia Pustaka. Jakarta. 